\title{
A novel cardioport for beating-heart, image-guided intracardiac surgery
}

\author{
Nikolay V. Vasilyev, MD, ${ }^{\mathrm{a}}$ Mitsuhiro Kawata, MD, PhD, ${ }^{\mathrm{a}}$ Christopher M. DiBiasio, PhD, ${ }^{\mathrm{b}}$ \\ Keith V. Durand, PhD, ${ }^{\mathrm{b}}$ Jonathan Hopkins, PhD, ${ }^{\mathrm{b}}$ Zachary J. Traina, MS, ${ }^{\mathrm{b}}$ Alexander H. Slocum, PhD, ${ }^{\mathrm{b}}$ and \\ Pedro J. del Nido, MD
}

\begin{abstract}
Objective: Intracardiac beating-heart procedures require the introduction and exchange of complex instruments and devices. To prevent potential complications such as air embolism and bleeding, a universal cardioport was designed and tested.
\end{abstract}

Methods: The design consists of a port body and a series of interchangeable sleeves. The port uses a fluid purg-
ing system to remove air from the instrument before insertion into the heart, and a valve system minimizes blood loss during instrument changes.

Results: The cardioport was tested ex vivo and in vivo in pigs $(n=5)$. Beating-heart procedures, such as septal defect closure and mitral valve repair, were modeled. Ex vivo trials $(n=150)$ were performed, and no air emboli were introduced using the port. In comparison, air emboli were detected in $40 \%$ to $85 \%$ of the cases without the use of the port-based purging system. Port operation revealed excellent ergonomics and minimal blood loss.

Conclusions: A novel cardioport system designed to prevent air entry and blood loss from transcardiac instrument introduction was shown to be an enabling platform for intracardiac beating-heart surgery. The port system improves safety and facilitates further development of complex instruments and devices for transcardiac beating-heart surgery. (J Thorac Cardiovasc Surg 2011;142:1545-51)

Video clip is available online.

Catheter-based intracardiac interventions to treat a variety of intracardiac and vascular defects have become the preferred approach for many lesions. The variety of devices that can be delivered via peripheral vessel access into the cardiac chambers has increased over the years largely because of improved manufacturing technology. However, there are interventional tools and devices that are difficult to deliver because of their size and complexity, and damage to

From the Department of Cardiac Surgery, ${ }^{\text {a }}$ Children's Hospital Boston and Harvard Medical School, Boston, Mass; and Department of Mechanical Engineering, ${ }^{\mathrm{b}}$ Massachusetts Institute of Technology, Cambridge, Mass.

This work was supported by the Center for Integration of Medicine and Innovative Technology Award No. 07-026 (to P.J.D.N.), National Institutes of Health National Heart, Lung, and Blood Institute Award No. 5R01HL073647 (to P.J.D.N.), and Massachusetts Technology Transfer Center Award (to P.J.D.N., N.V.V.).

Disclosures: The equipment and technology used in the study were purchased using academic funds. The authors had full control of the design of the study, methods used, outcome measurements, analysis of data, and production of the written report.

Received for publication April 29, 2011; revisions received June 20, 2011; accepted for publication July 11, 2011; available ahead of print Aug 22, 2011.

Address for reprints: Nikolay V. Vasilyev, MD, Department of Cardiac Surgery, Children's Hospital Boston, Harvard Medical School, 300 Longwood Ave, Boston, MA 02115 (E-mail: nikolay.vasilyev@ childrens.harvard.edu).

$0022-5223 / \$ 36.00$

Copyright (C) 2011 by The American Association for Thoracic Surgery

doi:10.1016/j.jtcvs.2011.07.041 peripheral blood vessels by the large size catheters has been reported. ${ }^{1}$ Moreover, with a transcatheter peripheral approach, there is limited precision for device positioning and manipulation inside the beating heart because of the moving structures and catheter tip control from the long distance. These limitations have led surgeons to develop transcardiac approaches for intracardiac procedures. Thus, transcardiac beating-heart surgical techniques that avoid use of cardiopulmonary bypass have evolved rapidly over the past decade and now are becoming more widely applied. ${ }^{2}$ In contrast with catheter-based interventions, transcardiac procedures have the advantage of providing a more direct route for device deployment or tissue manipulation, avoiding the often complex trajectory required for peripheral access, and providing a more stable tool tip inside the beating heart. Also, they are not as limited by the size constraints of peripheral vessels. Various devices can be introduced directly through the heart wall with echocardiographic, fluoroscopic, or magnetic resonance imaging guidance. For example, transapical left ventricular access is currently widely applied for aortic valve replacement and is even proposed for evolving techniques for mitral valve repair and closure of ventricular septal defects (VSDs). ${ }^{3-7}$

With an impending growing complexity of the instruments and devices for transcardiac repair, we anticipate the need to introduce these instruments safely inside the beating heart, minimizing blood loss and the risk of introduction of air emboli. In addition, depending on the procedure, some surgical tools may need to be introduced into the cardiac chamber 


\section{Abbreviations and Acronyms \\ $2 \mathrm{D}=2$-dimensional \\ $3 \mathrm{D}=3$-dimensional \\ $\mathrm{VSD}=$ ventricular septal defect}

multiple times during a single procedure. Thus, having the ability for easy and safe instrument exchange is of potential benefit. The risk associated with the introduction of large air bubbles into the cardiac chamber has been associated with end-organ injury, including stroke. ${ }^{8}$

The goal of our project was to develop and evaluate a universal transcardiac port (cardioport) that allows introduction of a variety of tools and facilitates multiple instrument insertions and exchanges, but prevents introduction of air into the cardiac chamber and bleeding during port placement and instrument exchanges.

\section{MATERIALS AND METHODS}

\section{Port Design Requirements and Implementation}

The key design requirements for the cardioport included the following: (1) direct access of surgical tools into any of the cardiac chambers from various angles; (2) prevention of introduction of air emboli detectable by echocardiography into the heart; (3) minimal blood loss from the heart during port introduction and operation, as well as during instrument introduction and exchanges; (4) minimal damage from the port to the heart wall and intracardiac structures; (5) optimal surgical ergonomics to allow single-hand operation; and (6) compatibility with imaging modalities that are used for guidance during beating-heart procedures (ie, ultrasound and fluoroscopy). These design requirements were incorporated into the components of the cardioport. ${ }^{9}$

The design consists of a port body (11 mm in diameter) and a series of interchangeable sleeves that form the interface between the port and the matching instrument (Figure 1). The tool sleeves are designed for a variety of surgical instruments ( $1-5 \mathrm{~mm}$ in diameter) and serve as adapters to standardize the mating interface between the inner surface of the cardioport body and the outer surface of each instrument. This design feature serves primarily to minimize the amount of air inside the port body around an instrument or device and at the same time allow smooth instrument movement within the cardioport. To minimize blood loss, a compliant trileaflet valve was developed and placed at the intracardiac tip of the cardioport. On the proximal side of the port, a series of O-rings seal the space between the instrument, tool sleeve, and body, preventing blood loss and introduction of air.

An additional design feature that improves safety of the procedure is the ability to "visualize" the cardioport using ultrasound imaging with minimal distortion or creation of artifact in the ultrasound image. ${ }^{10}$ This was implemented by manufacturing the port body and the sleeves out of polyvinylidene fluoride, or "Kynar," which is compatible with the ultrasound beam because it does not lead to ultrasound reverberations and artifact. The advantage of this feature is that the risk of injury to nearby intracardiac structures is minimized if the cardioport can be imaged as it penetrates the cardiac wall and is positioned within the cardiac chamber.

\section{Port Operation}

First, the port body with an obturator is inserted into the heart through a purse-string suture. Then, a tool sleeve, selected for a particular instrument or device, is inserted into the port body. The instrument is inserted into the tool sleeve and pushed forward until the distal tip of the instrument
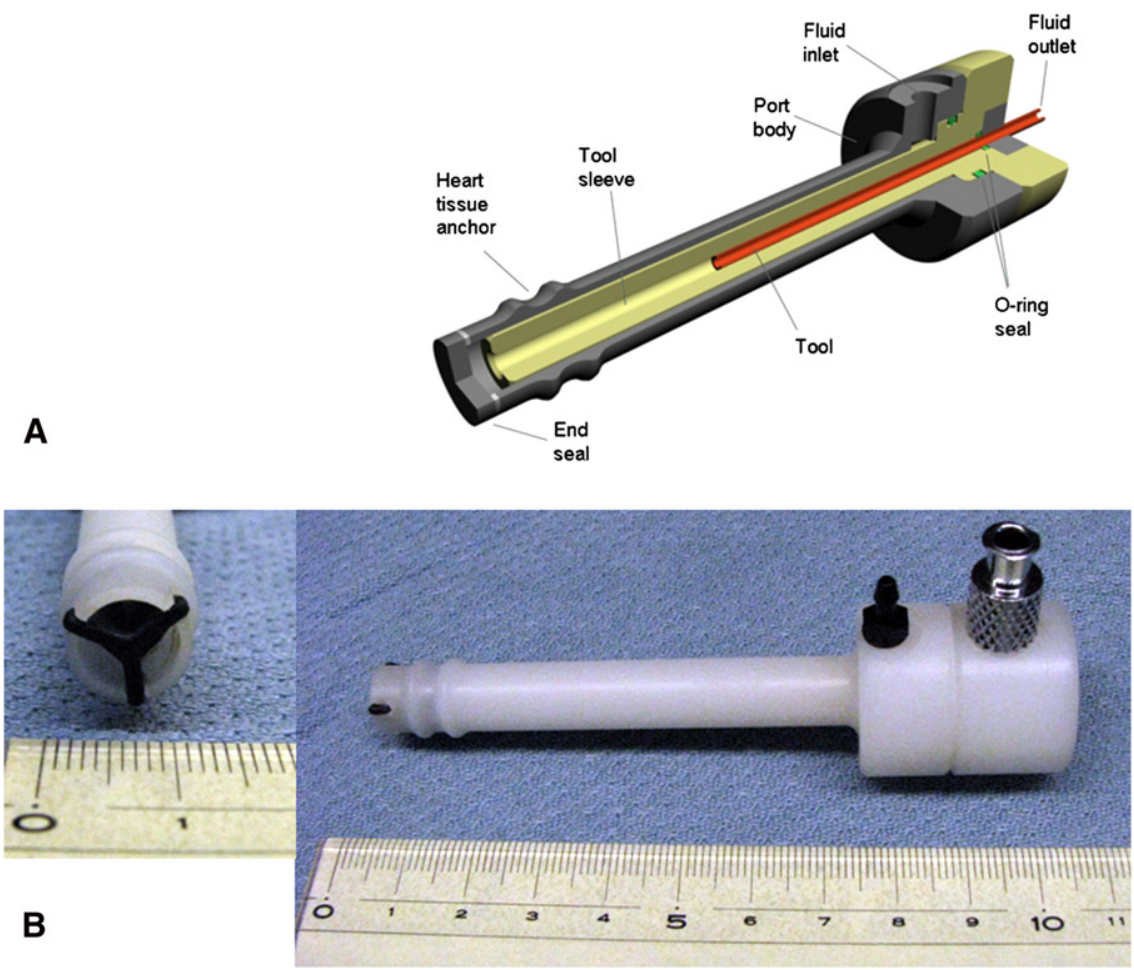

FIGURE 1. Fully assembled cardioport. A, Schematic drawing of the port showing the key components of the fluid purging and valve systems. B, Actual port with one of the tool sleeves inserted. Inset depicts the trileaflet valve at the intracardiac tip of the cardioport. 
has just reached the valve located at the distal end of the port body. Then, to remove air bubbles, an active fluid purging system is activated inside the instrument and the port (Video 1). The fluid inflow of the system is connected to the port body, and the outflow is connected to an instrument via Luer lock connection. Standard wall suction is applied at the outflow on the instrument, and a fluid reservoir (heparinized saline) is connected to the inflow. When the system is activated, the suction is applied through and around the instrument via the tool sleeve. This induces rapid flow of saline from a reservoir through the gap between the port body and the tool sleeve and through the instrument to ensure complete de-airing. The valve at the end of the cardioport body prevents blood from entering the port while fluid is circulating. Complete purging of the port and instrument is completed in approximately 5 seconds. After purging, the instrument is inserted inside the heart and used for surgical manipulations. This maneuver is repeated each time an instrument or device is inserted into the heart. After the procedure is completed, the cardioport is removed, and the pursestring suture is tied in a standard manner.

\section{Ex Vivo Testing}

The repeatability tests were conducted in a water tank equipped with ultrasound imaging. Effectiveness of air bubble removal, sturdiness of the port components, surgical ergonomics, and ease of port operation were evaluated. The port and presence of air bubbles were visualized by 2-dimensional (2D) and 3-dimensional (3D) echocardiography using the X4 matrix transducer on a SONOS 7500 system (Philips Healthcare, Andover, Mass). A standard 9F introducer sheath (Arrow International, Reading, $\mathrm{Pa}$ ) was used as a control.

\section{Animal Trials}

The experimental protocol was approved by the Children's Hospital Boston Institutional Animal Care and Use Committee. All animals received humane care in accordance with the 1996 Guide for the Care and Use of Laboratory Animals recommended by the US National Institute of Health.

In Yorkshire pigs weighing 60 to $70 \mathrm{~kg}(\mathrm{n}=5)$, beating-heart interventions such as atrial septal defect closure, VSD closure, and mitral valve repair were modeled as previously described. ${ }^{7,11,12}$ Briefly, animals were anesthetized by intramuscular injection of tiletamine/zolazepam $(7 \mathrm{mg} /$ $\mathrm{kg}$ ) and xylazine $(4 \mathrm{mg} / \mathrm{kg})$, and intubated with a cuffed endotracheal tube and ventilated with a pressure control ventilator (Healthdyne 105; Healthdyne Technologies, Marietta, Ga). Anesthesia was maintained with $2 \%$ to $3 \%$ isoflurane. A median sternotomy or left side thoracotomy was performed; a few stay sutures were placed on the pericardium to optimize access to the cardiac chambers. Epicardial 2D and 3D echocardiography were used for procedure imaging and air bubbles visualization with the X7-2 matrix transducer on an IE33 system (Philips Healthcare, Andover, Mass). Purse-string sutures of 3-0 or 4-0 polypropylene were placed on the heart wall for the cardioport insertion into the each chamber. After intravenous heparin administration (100 U/ $\mathrm{kg}$ ), the port was introduced into both right and left atria and ventricles. Effectiveness of air removal, occurrence of bleeding during port and instrument manipulations, and surgical ergonomics were tested. Introduction of the instruments through a conventional $9 \mathrm{~F}$ sheath and through the port, both after prior flushing but without use of the fluid purging system, served as a control.

\section{RESULTS}

\section{Ex Vivo Testing}

For each tool sleeve $(n=3)$, we inserted the tool, purged it, and then imaged the tip of the port as the tool passed through the end valve. This was repeated 50 times for each sleeve. All the components of the port system
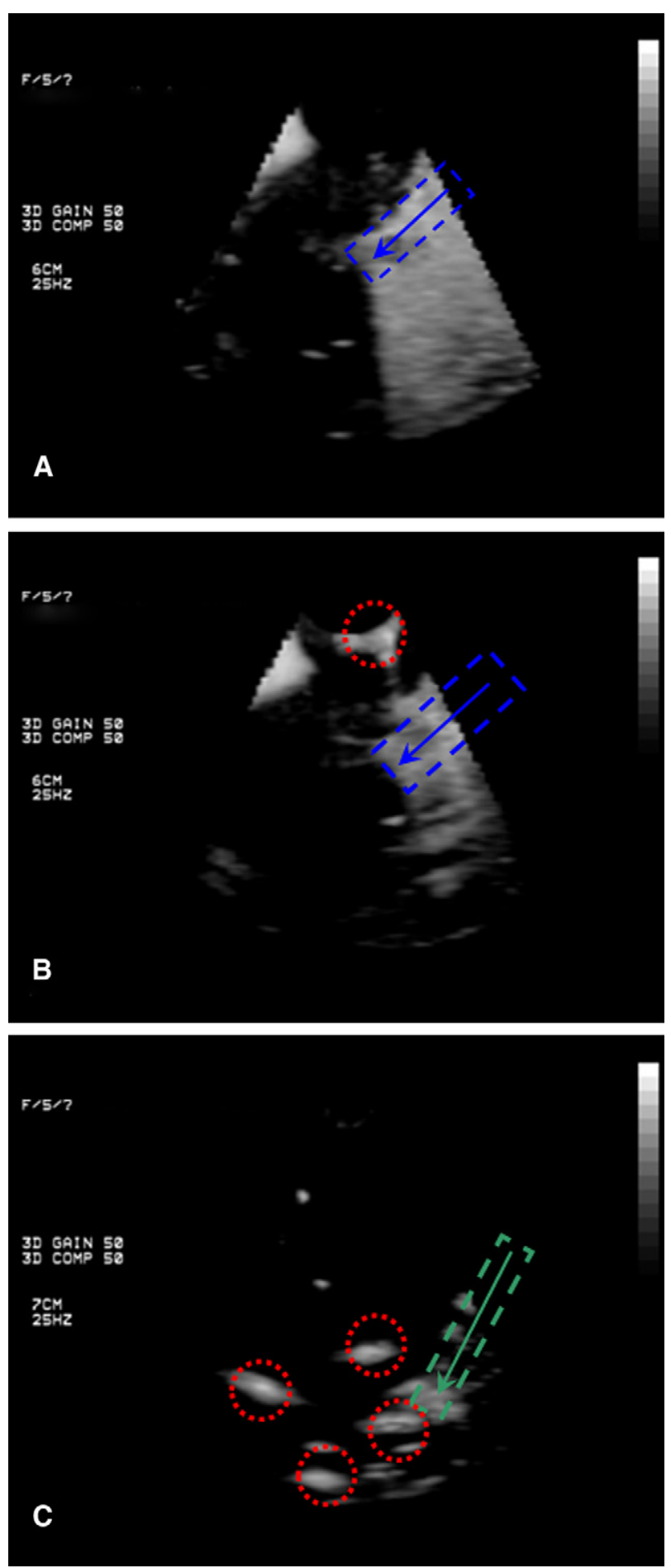

FIGURE 2. Water tank port testing under 3D echocardiography. A, After de-airing the port, no bubbles are present. B, Control: Without de-airing the port, large bubbles are present. C, Control with an introducer sheath: Multiple large bubbles are present. Cardioport (blue dashed line); introducer sheath (green dashed line); air bubbles detected (red dotted circle). The direction (arrow) of the instrument insertion. 

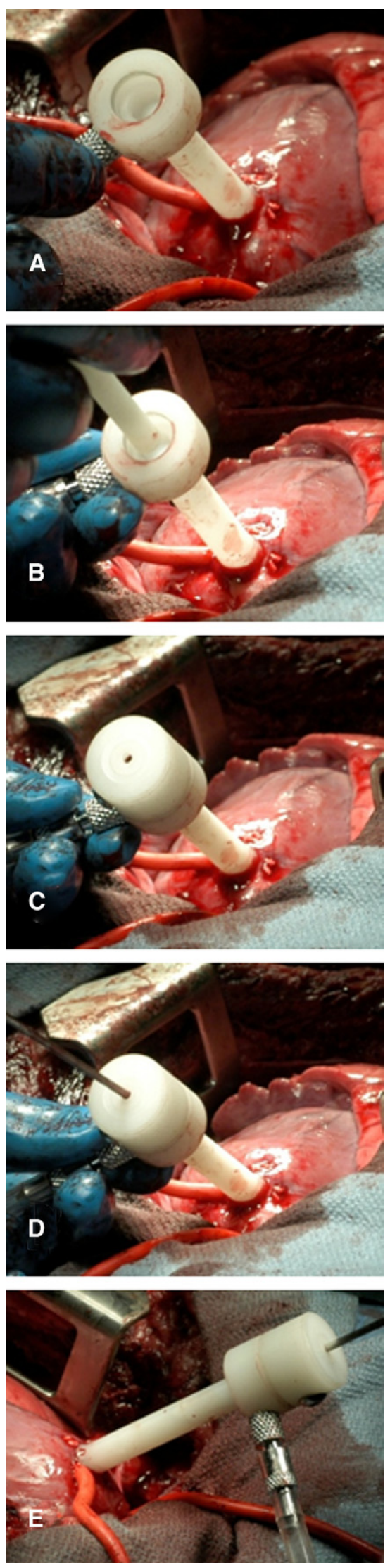

were operable throughout the tests. No air bubbles were visualized by $2 \mathrm{D}$ and $3 \mathrm{D}$ ultrasound. In contrast, we detected air bubbles after every tool insertion when using the conventional introducer or the unpurged port system (Figure 2).

\section{Large Animal Experiments}

Five series of trials were performed. In the first experiment, the port was introduced into the left ventricle, and operational durability of the system was tested in the presence of blood, inside the high-pressure chamber, without introduction of instruments. In all the subsequent experiments $(\mathrm{N}=4)$, the port was introduced into each of the 4 cardiac chambers, and instruments for beating-heart procedures were introduced (Figure 3). We used the modified instruments that were previously developed for atrial septal defect and VSD patch closure and for mitral valve repair. ${ }^{711,12}$ In particular, our tissue anchor deployment device was modified by adding the features for fluid flushing through its shaft.

Air was completely removed in all the instrument insertions (6-10 trials per chamber), and 2D and 3D ultrasound images showed no air emboli. In contrast, air emboli were detected in $40 \%$ to $85 \%$ of the cases of instruments insertion without use of the purge system (Figure 4, Video 1). Port operation exhibited excellent surgical ergonomics, and single-handed control and stabilization of the port was observed in all the animal trials. Instrument introduction and exchange were fast and smooth. The operator was able to reach all the desired intracardiac structures with the cardioport, without injury to the heart wall. No bleeding occurred in any of the cases throughout the procedure, during port placement, instruments introduction and exchanges, and port removal.

\section{Cardioscopy Port}

The cardioport can also be coupled to an imaging system, such as a conventional optical telescope for direct visualization or even an ultrasound crystal array for ultrasound imaging. After our initial experience with cardioscopy-assisted beating-heart procedures, ${ }^{11}$ we have designed a next-generation cardioscopy port that combines the features of the current cardioport system with additional optical imaging (Figure 5). The 14-mm cardioport was manufactured out of implantable grade PolyEtherEtherKetone. The inner compartment of the port has an exchangeable transparent plastic bulb at the end. It houses 

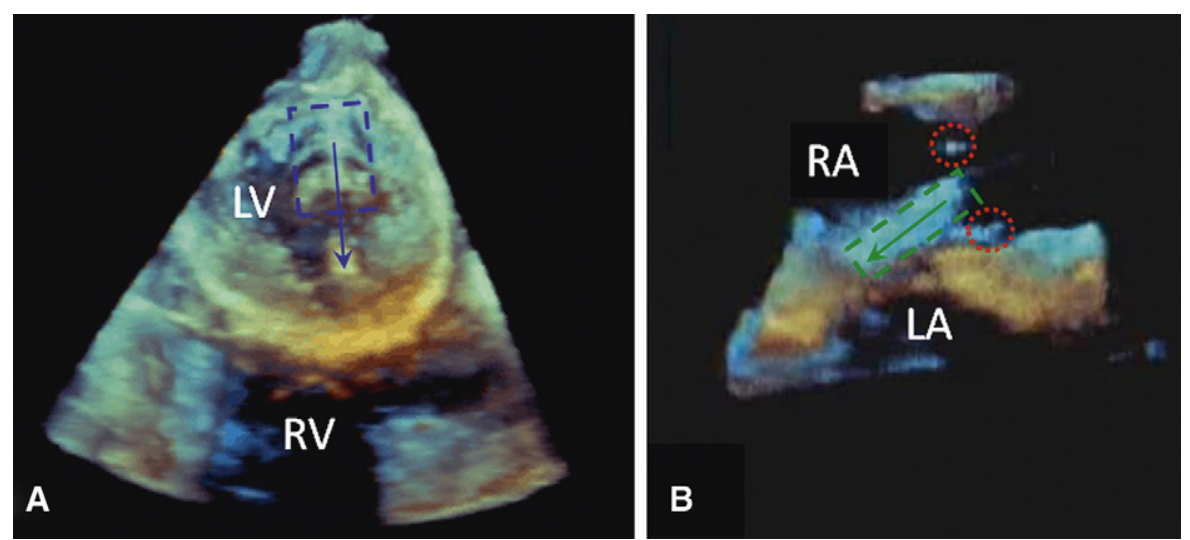

FIGURE 4. Intraoperative epicardial 3D echocardiography. A, VSD closure: Cardioport is inserted through the apex of the left ventricle, and the active fluid purging system is used; no air bubbles are detected. B, Atrial septal defect closure: Standard introducer sheath is used after prior flushing; air bubbles are detected. Cardioport (blue dashed line); introducer sheath (green dashed line); air bubbles detected (red dotted circle). The direction (arrow) of the instrument insertion. $R A$, Right atrium; $L A$, left atrium; $R V$, right ventricle; $L V$, left ventricle.

a standard 5-mm telescope for imaging. The bulbs with various geometries can be mounted on the tip of the port depending on the procedure. The outer working channel is $3 \mathrm{~mm}$ in diameter and used for instrument access. The port was designed for a particular set of instruments, which eliminated the need for tool sleeves. The valve and fluid purging systems were successfully adapted from the current cardioport.

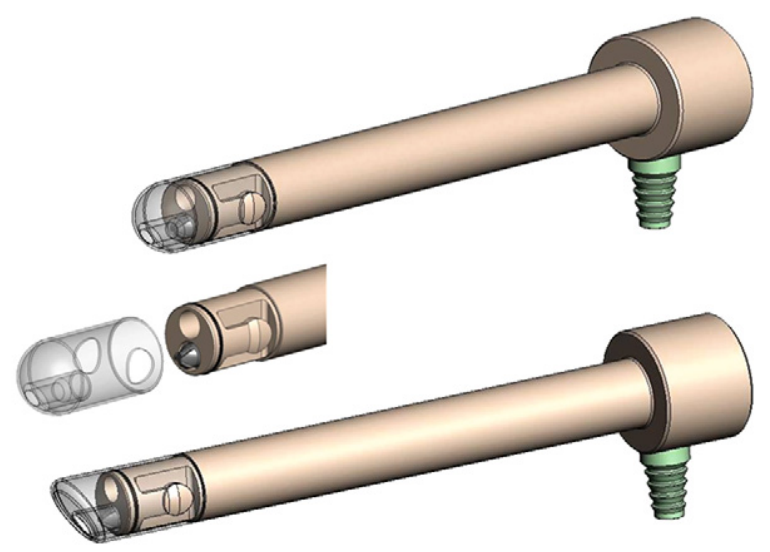

A

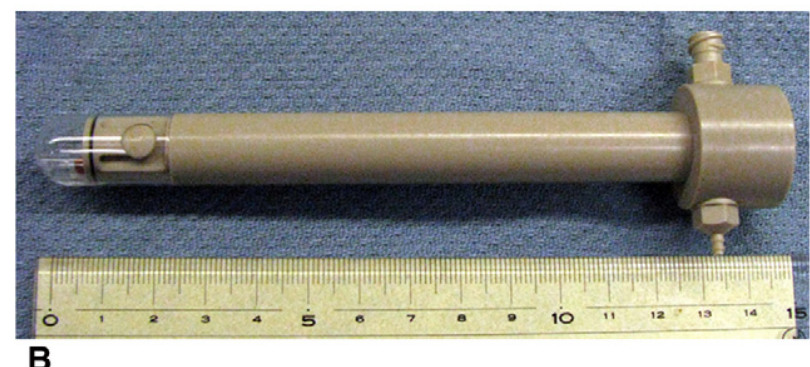

FIGURE 5. Next-generation cardioscopy port. A, Schematic drawing of the port showing exchangeable transparent plastic bulbs. B, Actual port with the spherical bulb.

\section{DISCUSSION}

With recent advancements in intracardiac devices and imaging technologies, a growing variety of instruments have been used inside the beating heart. This includes not only traditional stent-based devices but also more complex instruments, such as graspers, staplers, and patch deployment systems. ${ }^{2}$ Despite the growing number and complexity of procedures, there are few if any available universal cardioport systems that facilitate safe and effective instruments introduction and exchange.

Our group has previously reported the use of modified ports developed for other port-access procedures, such as thoracoscopic or laparoscopic surgery, and used them for intracardiac beating-heart, image-guided interventions in an experimental setting. ${ }^{13}$ However, after initial promising results, we found that such ports were not optimal for the work requirements of beating-heart transcardiac interventions, primarily because of the risk of air embolism during instrument introduction. Similar findings have been reported by others. Downing and colleagues ${ }^{14}$ tested a $15-\mathrm{mm}$ custom-designed port in beating-heart mitral valve repair, where the port was introduced into the left atrium. Although the port worked adequately allowing the procedure to be completed, air introduction was encountered in all 6 animals: minimal in 2, mild in 3, and moderate in 1 .

Other investigators have proposed a universal system for instrument introduction. Guiraudon and colleagues ${ }^{15}$ developed the universal cardiac introducer made of vascular graft material and assembled out of 2 components: an attachment cuff and an airlock chamber with up to 4 sleeves for introduction of various instruments and devices. The cuff is sutured to the cardiac wall, and intracardiac access is controlled with a vascular clamp. Instrument access inside the sleeves is controlled with snares. The airlock chamber acts as an air bubble trap, with the sleeves positioned 
vertically well above the heart port access. A saline line is connected to the airlock chamber to assist with de-airing. This port system is characterized by significant size and complexity. In addition, it may be challenging to use such a design for access into the high-pressure cardiac chambers, especially the left ventricle.

The advantage of our system is that an active fluid purging system is used, which ensures complete elimination of air bubbles from the instrument shaft before its entry into the cardiac chamber. Furthermore, the valve system prevents bleeding during instrument introduction and exchanges and allows port placement into high-pressure chambers from various angles, which may be necessary during image-guided, beating-heart transcardiac procedures. When the fluid purging system is enabled, the pressure in the port body becomes less than the pressure in the cardiac chambers. The compliant trileaflet valve was designed to exploit this pressure differential to seal against blood loss. In fact, as the pressure differential increases the seal becomes even stronger because of the design of the compliant valve's shape. It should be noted that the internal volume of the port body was also minimized to prevent blood loss during tool insertion and operation when the trileaflet valve is open. Furthermore, the availability of different size instrument sleeves allows the use of most conventional instruments and novel devices to be introduced via the port. In addition, although the current cardioport diameter is large, it can be reduced substantially for introduction into higher pressure chambers, such as the left ventricle, which will further reduce the size of the defect at the site of port introduction into the heart.

Additional important functionality of the cardioport system is to incorporate optical imaging. Video-assisted cardioscopy using visible wavelength light provides detailed, high-magnification imaging of the tools and the target. However, use of visible wavelength light requires that blood be physically displaced between the optical window of the cardioport and the target structures. This results in a limited field of view. Although the described procedures can be performed in the beating heart with the current system, use of infrared light may improve the field of view. Infrared light permits limited transmission through blood, ${ }^{16}$ but the depth of field of the current infrared systems is still less than 1 to $2 \mathrm{~cm}$, making navigation through the cardiac structures difficult. An additional limitation of the current infrared systems is that they have a relatively low frame rate because of the image processing time required, which makes visualization of rapidly moving structures, such as heart valves, difficult. Some of these limitations may be overcome by redesigning the location of the infrared light detector, which reduces light loss through the transmission fibers. If implemented, this may enable 2- or multiple-port operation inside the beating heart. Moreover, it would open a possibility of designing multifunctional tools for beating-heart intracardiac interventions, such as developed for gastroenterologic procedures. ${ }^{17}$ As for current procedures, we believe that the key to success in safe navigation inside the beating heart is still to use combined, or hybrid, imaging. Fluoroscopy provides a "big picture" view for navigation toward cardiac chambers, and 3D echocardiography can give surgeons superior large-volume spatial orientation, whereas cardioscopy offers a detailed, highmagnification view of the tool as it interacts with the target structure.

\section{CONCLUSIONS}

We have developed a novel cardioport system for the safe and easy introduction of surgical tools into all the cardiac chambers. Use of the port improves safety of beatingheart procedures and facilitates further development of more complex instruments and devices. This technology may be an enabling platform for intracardiac imageguided, beating-heart surgery.

\section{References}

1. Van Mieghem NM, Nuis RJ, Piazza N, Apostolos T, Ligthart J, Schultz C, et al. Vascular complications with transcatheter aortic valve implantation using the 18 Fr Medtronic CoreValve System: the Rotterdam experience. EuroIntervention. 2010;5:673-9.

2. Perrin DP, Vasilyev NV, Novotny P, Stoll J, Howe RD, Dupont PE, et al. Image guided surgical interventions. Curr Probl Surg. 2009;46:730-66.

3. Walther T, Simon P, Dewey T, Wimmer-Greinecker G, Falk V, Kasimir MT, et al. Transapical minimally invasive aortic valve implantation: multicenter experience. Circulation. 2007;116(11 Suppl):I240-5.

4. Bajona P, Katz WE, Daly RC, Zehr KJ, Speziali G. Beating-heart, off-pump mitral valve repair by implantation of artificial chordae tendineae: an acute in vivo animal study. J Thorac Cardiovasc Surg. 2009;137:188-93.

5. Núñez-Gil IJ, Gonçalves A, Rodríguez E, Cobiella J, Marcos-Alberca P, Maroto L, et al. Transapical mitral valve-in-valve implantation: a novel approach guided by three-dimensional transoesophageal echocardiography. Eur J Echocardiogr. 2011;12:335-7. Epub 2011 Mar 3.

6. Seeburger J, Borger MA, Tschernich H, Leontjev S, Holzhey D, Noack T, et al. Transapical beating heart mitral valve repair. Circ Cardiovasc Interv. 2010;3: 611-2.

7. Vasilyev NV, Melnychenko I, Kitahori K, Freudenthal FP, Phillips A, KozlikFeldmann R, et al. Beating-heart patch closure of muscular ventricular septal defects under real-time three-dimensional echocardiographic guidance: a preclinical study. J Thorac Cardiovasc Surg. 2008;135:603-9.

8. Stump DA, Kon NA, Rogers AT, Hammon JW. Emboli and neuropsychological outcome following cardiopulmonary bypass. Echocardiography. 1996;13: $555-8$.

9. DiBiasio CM, Durand KV, Hopkins J, Traina Z, Slocum A, Vasilyev NV, del Nido PJ. Design of a surgical port for minimally invasive beating-heart intracardial procedures. J Med Device. In press.

10. Huang J, Triedman JK, Vasilyev NV, Suematsu Y, Cleveland RO, Dupont PE. Imaging artifacts of medical instruments in ultrasound-guided interventions. $\mathrm{J} \mathrm{Ul}$ trasound Med. 2007;26:1303-22.

11. Vasilyev NV, Martinez JF, Freudenthal FP, Suematsu Y, Marx GR, del Nido PJ. Three-dimensional echo and videocardioscopy-guided atrial septal defect closure. Ann Thorac Surg. 2006;82:1322-6.

12. Yuen SG, Kesner SB, Vasilyev NV, Del Nido PJ, Howe RD. 3D ultrasoundguided motion compensation system for beating heart mitral valve repair. Med Image Comput Comput Assist Interv. 2008;11(Pt 1):711-9.

13. Suematsu Y, Marx GR, Triedman JK, Mihaljevic T, Mora BN, Takamoto S, et al. Three-dimensional echocardiography-guided atrial septectomy: an experimental study. J Thorac Cardiovasc Surg. 2004;128:53-9. 
14. Downing SW, Herzog WA Jr, McLaughlin JS, Gilbert TP. Beating-heart mitral valve surgery: preliminary model and methodology. J Thorac Cardiovasc Surg. 2002;123:1141-6.

15. Guiraudon GM, Jones DL, Bainbridge D, Peters TM. Mitral valve implantation using off-pump closed beating intracardiac surgery: a feasibility study. Interact Cardiovasc Thorac Surg. 2007;6:603-7.
16. Grundfest WS, Val-Mejias J, Monnet E, Knight BP, Nazarian S, Berger RD, et al Real-time percutaneous optical imaging of anatomical structures in the heart through blood using a catheter-based infrared imaging system. Semin Thorac Cardiovasc Surg. 2007;19:336-41.

17. Rattner D, Kalloo A. ASGE/SAGES Working Group on Natural Orifice Translumenal Endoscopic Surgery, October 2005. Surg Endosc. 2006;20:329-33.

Access to The Journal of Thoracic and Cardiovascular Surgery Online is reserved for print subscribers!

Full-text access to The Journal of Thoracic and Cardiovascular Surgery Online is available for all print subscribers. To activate your individual online subscription, please visit The Journal of Thoracic and Cardiovascular Surgery Online, point your browser to http://www.mosby.com/itcvs, follow the prompts to activate your online access, and follow the instructions. To activate your account, you will need your subscriber account number, which you can find on your mailing label (note: the number of digits in your subscriber account number varies from 6 to 10). See the example below in which the subscriber account number has been circled:

\section{Sample mailing label}

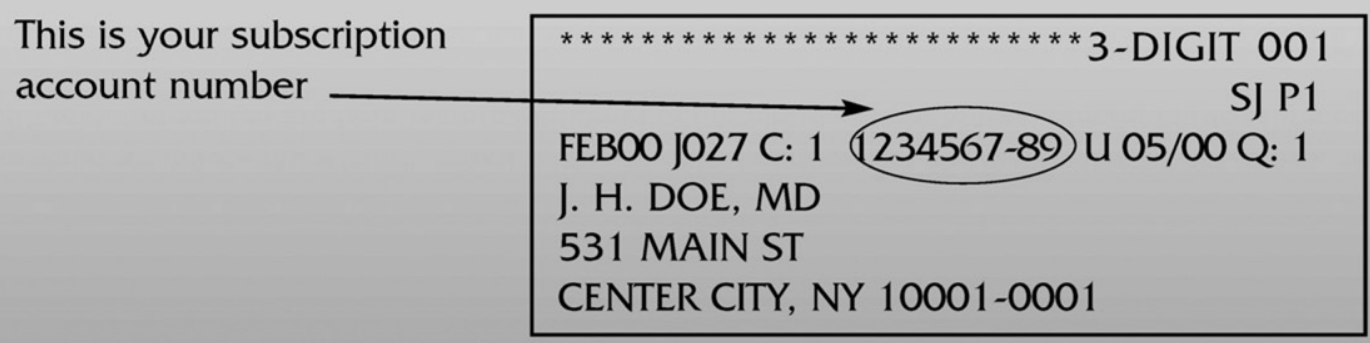

Personal subscriptions to The Journal of Thoracic and Cardiovascular Surgery Online are for individual use only and may not be transferred. Use of The Journal of Thoracic and Cardiovascular Surgery Online is subject to agreement to the terms and conditions as indicated online. 